\title{
The AO Trauma CPP Bone Infection Registry. epidemiology and outcomes on Staphylococcus aureus infection in long bones and joints
}

\section{Mario Morgenstern}

Universitatsspital Basel

Christoph Erichsen

BG Unfallklinik Murnau

Matthias Militz

BG Unfallklinik Murnau

Zhao Xie

Third Military Medical University Southwest Hospital

Peng Jiachen Peng

Zunyi Medical University

James Stannard

University of Missouri Health Care

Willem-Jan Metsemakers

Katholieke Universiteit Leuven Universitaire Ziekenhuizen Leuven

Dirk Schaefer

Universitatsspital Basel

Volker Alt

Universitatsklinikum Regensburg

Kjeld Soballe

Aarhus Universitet

Michael Nerlich

Universitat Regensburg

Richard E. Buckley

Foothills Medical Centre

Michael Blauth

Medizinische Universitat Innsbruck

Michael Suk

Geisinger Medical Center

Frankie Leung

University of Hong Kong

Jorge Barla 
Hospital Italiano de Buenos Aires

\section{Kiminori Yukata}

"Hiroshima Daigaku"

\section{Bi Qing}

Zhejiang Gongshang University

\section{Edward M Schwarz}

University of Rochester

Stephen L. Kates ( $\nabla$ stephen.kates@vcuhealth.org )

https://orcid.org/0000-0003-0005-8694

\section{Research article}

Keywords: Staphylococcus aureus, bone infection registry, implant related infection, prosthetic joint infection, fracture related infection, bone infection, osteomyelitis, clinical outcomes, MRSA

Posted Date: January 23rd, 2020

DOl: https://doi.org/10.21203/rs.2.21674/v1

License: (c) (7) This work is licensed under a Creative Commons Attribution 4.0 International License. Read Full License 


\section{Abstract}

\section{Background}

Bone infection is a serious complication associated with orthopedic surgery, and Staphylococcus aureus (S. aureus) is a common pathogen. As the optimal treatment requires an understanding of the patientspecific host-pathogen interaction, we developed a biospecimen registry (the AO Trauma CPP Bone Infection Registry) to collect clinical data, bacterial isolates, and serum from patients treated for bone infection caused by $S$. aureus.

\section{Methods}

A prospective multicenter multicontinental registry with a follow-up period of 12 months was set up to include adult patients (18 years or older) with culture-confirmed $S$. aureus infection in long bones after fracture fixation or arthroplasty. Baseline patient attributes and details on infections and treatments were recorded. Blood and serum samples were taken at baseline, 6, and 12 months. Patient outcomes were assessed with the Short Form-36, Parker Mobility Score, and Katz Activities of Daily Living at baseline, 1, 6 , and 12 months. Complications, re-hospitalization, and outcomes were recorded. Aside from descriptive summary analyses, changes from baseline were analyzed using the mixed-effects model and Wilcoxon sign rank test. Analyses using full analysis population and per protocol population were performed, and when appropriate, additional sensitivity analyses. This study was registered in ClinicalTrials.gov: NCT01677000.

\section{Results}

Two hundred and ninety-two patients with infections originating from fracture fixation $(n=157,53.8 \%)$, prosthetic joint infection ( $n=86,29.5 \%)$, and osteomyelitis $(n=49,16.8 \%)$ were enrolled (Table 1$)$. Methicillin resistant $S$. aureus was detected in 82 patients $(28.4 \%)$, with the highest proportion found among patients from North American sites $(n=39,48.8 \%)$ and the lowest from Central European sites $(n=18,12.2 \%)$. Patient outcomes had improved statistically significant at 6 and 12 months in comparison to baseline. The SF-36 Physical Component Summary mean (95\% Cl) score, however, did not reach 50, at 12 months. The cure rate at the end of the study period was $62.1 \%$.

\section{Conclusion}

The AO Trauma CPP Bone Infection Registry provides unique insights into the epidemiology and outcomes of $S$. aureus long-bone infections. It also contains annotated biospecimens for future research.

Although patients' health status improved after treatment, less than two-thirds were cured at one year.

\section{Background}


Infection represents one of the most feared complications after fracture fixation and arthroplasty (1). The emergence of multidrug-resistant organisms such as methicillin resistant $\mathrm{S}$. aureus (MRSA) have made treatment more challenging (2). Multiple revision surgeries and long-term antimicrobial therapy are often needed to treat infection and restore function. Although surgical treatment options have improved over time, a considerable knowledge gap remains with respect to the relationship between treatment protocols, risk factors, and patient outcomes $(3,4)$.

A recently published systematic literature review (93 studies and 3701 patients) analyzed treatment concepts and outcome of fracture-related infection (FRI) (5). The authors reported an overall treatment success rate of $85 \%$ and a recurrence rate of $9 \%$. This review underscored the heterogeneity in treatment protocols and the lack of accepted standardized outcome parameters (e.g. quality of life) and showed that critical data such as patient factors, causative pathogens, and treatment details for a better understanding of the relationship between FRI treatment protocols and patient outcomes were lacking. Further, the 2018 International Consensus Meeting on Musculoskeletal Infection (ICM 2018), comprised of 869 delegates from 92 countries (6), failed to reach an agreement that "moderate" evidence exists on the subjects of immunotherapy and immunoprophylaxis for the treatment of implant-associated infections, and concluded that the elucidation of patient-specific host-pathogen interactions is a research priority in this field (7).

To help understand the interplay among patient demographics, comorbidities, treatment modalities, patient-specific host immunity against the causal pathogen(s), and outcomes, we established an international multicenter biospecimen registry of S. aureus infection in long bones and joints (the AO Trauma CPP Bone Infection Registry) to collect clinical data, bacterial isolates, whole blood, and sera. The development and challenges in setting up this registry have recently been reported (8), and the manuscript on the microbiological and immunological results of this registry is in preparation. Here we report our findings on the epidemiology and outcomes of S. aureus long-bone infections in this registry.

\section{Methods}

The current investigation was a prospective, observational, nonrandomized case-series of patients with bony infections (registered in ClinicalTrials.gov: NCT01677000). Study conduct, data management, patient consent (including the use of collected biomaterials for future studies), and ethics approval were as described previously (8). Baseline assessments were done at the time the patients consented to participate in the study. The follow-up (FU) period was 12 months with planned visits at 1, 6, and 12 months.

Inclusion and exclusion criteria

Adult patients (aged 18 years or older) with confirmed S. aureus (either methicillin resistant or sensitive) infection involving a long bone (femur, tibia, fibula, humerus, radius, ulna, and clavicle) due to fracture fixation, osteomyelitis or arthroplasty were eligible (8), disregarding the stage of disease progression and treatment history. S. aureus infections were confirmed by positive deep wound cultures from baseline 
examinations or by a prior definitive diagnosis of ongoing S. aureus infection (deep wound culture) from the surgical site by the treating surgeon. Prisoners, patients unable to give consent or could not attend the FU visits were excluded. Patients with history of substance abuse that would preclude reliable assessments were also excluded.

\section{Objectives}

The aim of this article is to describe the results of the AO Trauma CPP Bone Infection Registry: its patient population, baseline characteristics, infection details, cryopreserved biomaterials, treatment details, complications, functional outcomes, and quality of life after treatment.

\section{Outcome measures}

Patient attributes, medical history, comorbidities (Charlson comorbidity index) (9), medications, treatment approaches, and hospital course were recorded at baseline. Nasal swabs, deep wound swabs, serum, and whole blood samples were taken only at baseline; laboratory blood tests performed through the study sites and serum samples collected for later testing in central laboratories were taken at baseline, 6, and 12 months. Short Form-36 version 2 (SF-36 v2) $(10,11)$, Parker Mobility Score (PMS) (12), and Katz Index of Independence in Activities of Daily Living (Katz ADL) questionnaires $(13,14)$ were used to assess patients' physical and mental health, their mobility, and their degree of independence at baseline and at all FU visits.

As this registry did not interfere with standard of care, adverse events (AEs) as defined by ISO 14155 were not recorded. Procedure-related AEs (e.g. complications caused by collection of blood, nasal, and aerobic bacterial samples) were documented. In-hospital complications that led to prolonged hospitalization or re-admission were documented in the complication form; predefined events of medical relevance that required hospital admission or prolongation of existing hospitalization were also recorded.

\section{Short Form-36}

SF-36 questionnaire consists of 36 questions in eight different scales assessing both physical and mental health status $(10,11)$. The scores range from 0 to 100 with higher scores representing better health status.

\section{Parker Mobility Score}

The PMS assesses patient mobility. The final score ranges from 0 to 9 points, with higher scores indicating higher function (12). If any of the three questions were missing, the total score was also set to missing.

Katz Index of Independence in Activities of Daily Living

Katz $A D L$ is a 6-item questionnaire that assesses the independence in activities of daily living (bathing, dressing, toileting, transferring, continence, and feeding) $(13,14)$. If any of the six items was missing, the 
total grade was also marked as missing.

Healing status

Healing status was assessed at each FU as cured, healing, or other by the individual investigational sites according to their standard of care.

Establishment of the annotated biorepository and clinical laboratory tests

S. aureus strains were identified from the wound samples taken at baseline, and characterized as MRSA, and/or methicillin sensitive S. aureus (OSSA/MSSA) by local laboratories. The individual strains were cultured, cryopreserved, and labeled with the patient's deidentified registry number for subsequent analyses. Serum samples ( $10 \mathrm{ml}$ per patient) collected at baseline and the FU visits were cryopreserved and labeled with the patient's deidentified registry number for subsequent analyses.

Descriptive analyses of the level of glycated hemoglobin, C-reactive protein, white blood cell count, and erythrocyte sedimentation rate were performed by the local laboratories. Since these values were not particularly informative, they are not presented in this manuscript.

Statistical analysis

The current study aimed to characterize the patient demographics, disease and treatment characteristics, and outcomes, therefore no sample size calculation was required. The target sample size of 300 was calculated to allow the possibility of building a prognostic model with nine variables of interest assuming a binary outcome with an incidence of 30 events per 100 patients.

The "full analysis population" was defined as all eligible patients who gave written consent and commenced treatment within the study. The "per protocol population" was defined as patients who completed all FU visits.

Patient baseline characteristics, type of infection, hospitalization, and treatment details were analyzed using descriptive analyses. Continuous variables were summarized using mean and standard deviation (SD) for normally distributed data, whereas median and interquartile range (IQR) as well as minimum and maximum, were used for non-normally distributed data. Number and percentages were used for categorical variables.

SF-36 and PMS scores were analyzed using both descriptive statistics and mixed-effects models for repeated measures with an unstructured covariance. Katz ADL scores were analyzed by descriptive statistics and the changes from baseline were analyzed using Wilcoxon sign rank test. Outcome scores were analyzed first using data from the full analysis population and then repeated for the per protocol population.

The aggregated SF-36 physical and mental component summary scores (PCS and MCS, respectively) were transformed using the norm-based scoring with mean $=50$ and standard deviation $=10$ using the US 
population norm because its documentation of the algorithm is the best. In short, all scores above 50 can be interpreted as being above the US population average and all scores below 50 can be interpreted as being below the US population average. Although our study population was global, using this norm-based scoring helped ease the interpretation of the scores. The questionnaire used for this study was the standard (4-week recall) form.

The healing status was analyzed for both full analysis population and complete cases, i.e., patients whose assessment was available at all FU visits. SAS software (V9.4 Analytics Software \& Solutions, Cary, North Carolina 27513, USA) was used to perform all statistical analyses.

\section{Results}

\section{Patient disposition}

Patients were enrolled between November 2012 and August 2017 in 18 centers from ten countries in Europe (Germany, Switzerland, Austria, Belgium, and Denmark), Asia (China and Japan), North America (US and Canada) and South America (Argentina). In total, 292 patients gave written consent and commenced treatment within the study (the full analysis population) (8). Of the 292 patients, 147 (50.4\%) were recruited from Europe, 80 (27.4\%) from North America, 62 (21.2\%) from Asia, and 3 (1.0\%) from South America. A patient recruitment diagram shows the details of patient recruitment from the initial screening to the end of the study (Fig. 1). A detailed description of patient dropouts and deaths is provided in our previous publication (8).

\section{Baseline information and infection details}

The patient population was predominantly male $(n=203,69.5 \%)$, and otherwise healthy as indicated by the low Charlson comorbidity index (median $=0.0$, range $=0.0$ to 10.0) (Table 1). More than half of the patients ( $n=175 ; 59.9 \%$ ) had previously (within the three years prior to their inclusion in the current study) undergone orthopedic treatment related to the bone infection with a median number of treatments of 2.0 (range $=1.0$ to 20.0 ). 
Table 1

Patient characteristics, infection-, hospitalization- and treatment details

\begin{tabular}{|c|c|}
\hline \multicolumn{2}{|l|}{ Patient characteristics } \\
\hline Age [years], $\mathrm{n}$ & 292 \\
\hline Mean (sd) & $52.3(16.9)$ \\
\hline Min; Max & $18.0 ; 93.0$ \\
\hline Gender, n (\%) & 292 \\
\hline Female & $89(30.5)$ \\
\hline Male & $203(69.5)$ \\
\hline Place of residence prior to hospital admission, $\mathrm{n}(\%)$ & 292 \\
\hline Home & $263(90.1)$ \\
\hline Nursing Home & $17(5.8)$ \\
\hline Residential home & $1(0.3)$ \\
\hline Hospice care & $11(3.8)$ \\
\hline Body mass index $\left(\mathrm{kg} / \mathrm{m}^{2}\right), \mathrm{n}$ & 291 \\
\hline Mean (sd) & $28.5(7.1)$ \\
\hline Min; Max & $16.6 ; 68.1$ \\
\hline Charlson comorbidity index ${ }^{1}, \mathrm{n}$ & 274 \\
\hline Mean (sd) & $0.8(1.5)$ \\
\hline Min; Max & $0.0 ; 10.0$ \\
\hline \multicolumn{2}{|l|}{ Infection and hospitalization details } \\
\hline Onset of symptoms of infection (days before hospital admission), $\mathrm{n}$ & 292 \\
\hline Mean (sd) & $359.2(1795.7)$ \\
\hline Median (Q1; Q3) & $14.0(4.0 ; 80.0)$ \\
\hline Min; Max & $0.0 ; 17885.0$ \\
\hline Origin of infection, $\mathrm{n}(\%)$ & 292 \\
\hline Osteomyelitis & $49(16.8)$ \\
\hline \multicolumn{2}{|l|}{ * Calculated as 'Date of surgery' minus 'Admission date' } \\
\hline$\S$ Calculated as 'Admission date' minus 'Discharge date' & \\
\hline
\end{tabular}




\begin{tabular}{|c|c|}
\hline \multicolumn{2}{|l|}{ Patient characteristics } \\
\hline Fracture fixation infection & $157(53.8)$ \\
\hline Prosthetic joint infection & $86(29.5)$ \\
\hline Days between admission and surgery (days) ${ }^{2}, \mathrm{n}$ & 285 \\
\hline Mean (sd) & $4.8(17.3)$ \\
\hline Median (Q1; Q3) & $1.0(0.0 ; 4.0)$ \\
\hline Min; Max & $0.0 ; 230.0$ \\
\hline Duration of hospital stay (nights) ${ }^{3}, \mathrm{n}$ & 290 \\
\hline Mean (sd) & $29.9(31.9)$ \\
\hline Min; Max & $0.0 ; 247.0$ \\
\hline Admission Type, n (\%) & 292 \\
\hline Emergency & $63(21.6)$ \\
\hline Urgent & $127(43.5)$ \\
\hline Elective & $102(34.9)$ \\
\hline Discharge Destination n (\%) & 289 \\
\hline Home & $215(74.4)$ \\
\hline Nursing home & $40(13.8)$ \\
\hline Residential home & $3(1.0)$ \\
\hline Hospice care & $1(0.3)$ \\
\hline Transfer to other hospital & $30(10.4)$ \\
\hline \multicolumn{2}{|l|}{ Treatment details } \\
\hline Duration of surgery (skin-to-skin time) [min], n & 282 \\
\hline Mean (sd) & $96.9(68.7)$ \\
\hline Median (Q1; Q3) & $80.0(43.0 ; 132.0)$ \\
\hline Min; Max & $0.0 ; 539.0$ \\
\hline Which surgical procedures were performed?, n (\%)\# & 285 \\
\hline \multicolumn{2}{|l|}{ *Calculated as 'Date of surgery' minus 'Admission date' } \\
\hline$\S$ Calculated as 'Admission date' minus 'Discharge & \\
\hline
\end{tabular}




\begin{tabular}{|ll|}
\hline Patient characteristics & \\
\hline Debridement & $264(92.6)$ \\
\hline Implant removal & $132(46.3)$ \\
\hline Local antibiotic treatment & $121(42.5)$ \\
\hline Spacer placement & $78(27.4)$ \\
\hline Implant Exchange & $43(15.1)$ \\
\hline Amputation & $1(0.4)$ \\
\hline Revision of fixation & $14(4.9)$ \\
\hline Fusion & $1(0.4)$ \\
\hline Osteotomy & $17(6.0)$ \\
\hline Other* & $68(23.9)$ \\
\hline Route of systemic antibiotic administration, $n$ (\%) ${ }^{\#}$ & 277 \\
\hline Intravenous & $251(90.6)$ \\
\hline Oral & $101(36.5)$ \\
\hline Systemic antibiotics for how many days? [days] & \\
\hline Mean (sd) & $29.1(24.8)$ \\
\hline Median (Q1; Q3) & $24.0(12.0 ; 42.0)$ \\
\hline Min; Max & $1.0 ; 155.0$ \\
\hline * Calculated as 'Date of surgery' minus 'Admission date' & \\
\hline § Calculated as 'Admission date' minus 'Discharge date' & \\
\hline
\end{tabular}

The origin of infection was fracture fixation for open or closed fracture $(n=157,53.8 \%)$, prosthetic joint infection ( $n=86,29.5 \%)$, or osteomyelitis $(n=49,16.8 \%)$ (Table 1$)$.

Aside from S. aureus infection (MSSA/OSSA or MRSA), 46 patients (15.8\%) had infections involving additional organisms. The proportion of MRSA infection was the highest in patients recruited from North American study sites $(n=39,48.8 \%)$, followed by the ones recruited from Asian study sites $(n=25,40.3 \%)$ (Table 2). 
Table 2

Summary of SF-36 summary scores, Parker Mobility items and Katz ADL assessment over follow-up (full analysis population)

\begin{tabular}{|c|c|c|c|c|}
\hline & Visit & & & \\
\hline Variable & $\begin{array}{l}\text { Baseline } \\
\mathrm{N}=292\end{array}$ & $\begin{array}{l}1 \text { month } \\
N=265\end{array}$ & $\begin{array}{l}6 \text { months } \\
N=216\end{array}$ & $\begin{array}{l}12 \text { months } \\
N=196\end{array}$ \\
\hline \multicolumn{5}{|l|}{ Healing status } \\
\hline $\mathrm{n}$ & - & 265 & 212 & 190 \\
\hline Cured, n (\%) & - & $12(4.5)$ & $78(36.8)$ & $118(62.1)$ \\
\hline Healing, n (\%) & - & $229(86.4)$ & $122(57.5)$ & $57(30.0)$ \\
\hline Other, n (\%) & - & $24(9.1)$ & $12(5.7)$ & $15(7.9)$ \\
\hline \multicolumn{5}{|c|}{$\begin{array}{l}\text { SF-36 Physical Component } \\
\text { Summary (PCS) }\end{array}$} \\
\hline $\mathrm{n}$ & 271 & 253 & 210 & 191 \\
\hline Mean (sd) & $31.0(9.6)$ & $30.5(8.2)$ & $35.7(10.2)$ & $38.1(11.2)$ \\
\hline Median (Q1; Q3) & $\begin{array}{l}29.9(25.0 ; \\
37.5)\end{array}$ & $\begin{array}{l}29.8(24.2 \\
36.3)\end{array}$ & $\begin{array}{l}35.3(28.7 \\
43.5)\end{array}$ & $\begin{array}{l}38.1(29.3 \\
46.1)\end{array}$ \\
\hline Min; Max & $5.8 ; 59.6$ & $11.2 ; 53.6$ & $11.1 ; 60.1$ & $13.9 ; 60.7$ \\
\hline \multicolumn{5}{|c|}{$\begin{array}{l}\text { SF-36 Mental Component Summary } \\
\text { (MCS) }\end{array}$} \\
\hline $\mathrm{n}$ & 271 & 253 & 210 & 191 \\
\hline Mean (sd) & $42.6(14.3)$ & $43.4(14.4)$ & $47.6(12.9)$ & $47.6(13.4)$ \\
\hline Median (Q1; Q3) & $\begin{array}{l}42.6(31.9 \\
54.8)\end{array}$ & $\begin{array}{l}43.6(33.1 ; \\
54.8)\end{array}$ & $\begin{array}{l}48.6(38.2 ; \\
58.5)\end{array}$ & $\begin{array}{l}49.8(37.9 \\
58.2)\end{array}$ \\
\hline Min; Max & $10.0 ; 74.4$ & $10.5 ; 72.5$ & $18.1 ; 71.5$ & $5.4 ; 69.0$ \\
\hline \multicolumn{5}{|c|}{ Parker Mobility Score } \\
\hline $\mathrm{n}$ & 285 & 259 & 210 & 187 \\
\hline Mean (sd) & $4.8(3.1)$ & $4.3(2.9)$ & $6.2(2.6)$ & $7.0(2.3)$ \\
\hline Median (Q1; Q3) & $5.0(2.0 ; 7.0)$ & $5.0(2.0 ; 6.0)$ & $6.0(5.0 ; 9.0)$ & $7.0(6.0 ; 9.0)$ \\
\hline Min; Max & $0.0 ; 9.0$ & $0.0 ; 9.0$ & $0.0 ; 9.0$ & $0.0 ; 9.0$ \\
\hline \multicolumn{5}{|c|}{ KATZ ADL sum score } \\
\hline $\mathrm{n}$ & 282 & 255 & 205 & 187 \\
\hline
\end{tabular}




\begin{tabular}{|lllll|}
\hline \multicolumn{4}{|l|}{ Visit } \\
\hline Mean (sd) & $4.6(1.9)$ & $4.4(2.0)$ & $5.3(1.5)$ & $5.5(1.2)$ \\
\hline Median (Q1; Q3) & $6.0(3.0 ; 6.0)$ & $5.0(3.0 ; 6.0)$ & $6.0(5.0 ; 6.0)$ & $6.0(6.0 ; 6.0)$ \\
\hline Min; Max & $0.0 ; 6.0$ & $0.0 ; 6.0$ & $0.0 ; 6.0$ & $0.0 ; 6.0$ \\
\hline $\begin{array}{l}\text { Change from baseline in KATZ ADL } \\
\text { sum score, }\end{array}$ & & & & \\
\hline $\mathrm{n}$ & & 250 & 198 & 180 \\
\hline Worsening, n (\%) & $0(-)$ & $70(28.0)$ & $20(10.1)$ & $15(8.3)$ \\
\hline Maintenance, n (\%) & $0(-)$ & $128(51.2)$ & $102(51.5)$ & $94(52.2)$ \\
\hline Improvement, n (\%) & $0(-)$ & $52(20.8)$ & $76(38.4)$ & $71(39.4)$ \\
\hline
\end{tabular}

Hospitalization and treatment details

The median time from onset of infection symptoms till baseline hospitalization was 14 days. Urgent (within 1 day) hospital admission was required in $43.5 \%(n=127)$ and emergency (same day) admission in $21.6 \%(n=63)$. The remaining patients $(n=102 ; 34.9 \%)$ were admitted electively. Only three patients $(1.0 \%)$ received an ambulatory treatment. The median time between admission and surgery was one day. All but seven patients $(2.4 \%)$ received surgical treatment, whereas in more than half of the cases $(n=151$; $53.2 \%)$ a multistage procedure was applied. Surgical debridement was performed in most cases $(n=264$; $92.6 \%$ ). The mean duration of hospital stay was 30.2 days $(S D=31.9)$, ranging from one to 247 days. Systemic antibiotics were prescribed for all but eleven patients, and the median (Q1; Q3) treatment length was $24.0(12.0 ; 42.0)$ days. Among the 277 patients with known antibiotic treatment details, the predominant route of administration was intravenous $(n=251 ; 90.6 \%)$. Treatment details are summarized in Table 3. 
Table 3

SF-36 summary scores and Parker Mobility Score over follow-up - estimates from mixed effect model (full analysis population)

\begin{tabular}{|c|c|c|c|c|c|}
\hline Outcome & Visit & $\mathrm{n}$ & $\begin{array}{l}\text { Mean } \\
(95 \% \mathrm{Cl})\end{array}$ & $\begin{array}{l}\text { Change } \\
(95 \% \mathrm{Cl})\end{array}$ & $\begin{array}{l}P \\
\text { value }\end{array}$ \\
\hline \multirow[t]{4}{*}{$\begin{array}{l}\text { SF-36 Physical Component Summary } \\
\text { (PCS) }\end{array}$} & Baseline & 271 & $\begin{array}{l}30.9(29.7 ; \\
32.0)\end{array}$ & & \\
\hline & 1 month & 253 & $\begin{array}{l}30.5(29.5 \\
31.5)\end{array}$ & $\begin{array}{l}-0.4(-1.4 \\
0.6)\end{array}$ & 0.447 \\
\hline & $\begin{array}{l}6 \\
\text { months }\end{array}$ & 210 & $\begin{array}{l}35.5(34.2 \\
36.7)\end{array}$ & $4.6(3.3 ; 5.9)$ & $<.001$ \\
\hline & $\begin{array}{l}12 \\
\text { months }\end{array}$ & 191 & $\begin{array}{l}37.9(36.4 ; \\
39.3)\end{array}$ & $7.0(5.6 ; 8.4)$ & $<.001$ \\
\hline \multirow[t]{4}{*}{$\begin{array}{l}\text { SF-36 Mental Component Summary } \\
\text { (MCS) }\end{array}$} & Baseline & 271 & $\begin{array}{l}42.5(40.8 \\
44.2)\end{array}$ & & \\
\hline & 1 month & 253 & $\begin{array}{l}43.1(41.4 ; \\
44.8)\end{array}$ & $0.6(-1.0 ; 2.1)$ & 0.458 \\
\hline & $\begin{array}{l}6 \\
\text { months }\end{array}$ & 210 & $\begin{array}{l}47.1(45.4 ; \\
48.7)\end{array}$ & $4.5(2.9 ; 6.2)$ & $<.001$ \\
\hline & $\begin{array}{l}12 \\
\text { months }\end{array}$ & 191 & $\begin{array}{l}46.7(45.0 ; \\
48.5)\end{array}$ & $4.2(2.5 ; 6.0)$ & $<.001$ \\
\hline \multirow[t]{4}{*}{ Parker Mobility Score } & Baseline & 285 & $4.8(4.4 ; 5.1)$ & & \\
\hline & 1 month & 259 & $4.2(3.9 ; 4.6)$ & $\begin{array}{l}-0.5(-0.9 \\
-0.2)\end{array}$ & 0.002 \\
\hline & $\begin{array}{l}6 \\
\text { months }\end{array}$ & 210 & $6.2(5.9 ; 6.6)$ & $1.5(1.0 ; 1.9)$ & $<.001$ \\
\hline & $\begin{array}{l}12 \\
\text { months }\end{array}$ & 187 & $6.9(6.6 ; 7.2)$ & $2.1(1.8 ; 2.5)$ & $<.001$ \\
\hline
\end{tabular}

The lower leg (tibia / fibula) was the most frequently affected $(n=116 ; 40.7 \%)$ body region, followed by the knee joint $(n=60 ; 21.1 \%)$, the femur $(n=51 ; 17.9 \%)$ and the hip joint $(n=44 ; 15.4 \%)$. The infection was less commonly seen in the upper extremity (Clavicle: $n=1,0.4 \%$; shoulder: $n=5,1.8 \%$; humerus: $n=10$, $3.5 \%$; forearm: $n=15,5.3 \%)$. In 26 patients (8.9\%), more than one body region was affected.

Outcomes 
Table 4 summarizes the results of the mixed-effects model analyses on the SF-36 and PMS scores of the full analysis population. At 1 month, both the SF-36 mean $(95 \% \mathrm{Cl})$ PCS score $[30.5(29.5 ; 31.5)]$ and the PMS mean $(95 \% \mathrm{Cl})$ score $[4.2(3.9 ; 4.6)]$ were lower than the baseline scores $[30.9(29.7 ; 32.0)$ and 4.8 $(4.4 ; 5.1)$, respectively]; the difference was statistically significant for the PMS scores $(p=0.002)$, but not statistically significant for the SF-36 PCS scores $(p=0.447)$. At 6 months, the SF-36 mean $(95 \% \mathrm{Cl})$ scores were PCS, $35.5(34.2 ; 36.7)$ and MCS, $47.1(45.4 ; 48.7)$; by 12 months, these were $37.9(36.4 ; 39.3)$ and $46.7(45.0 ; 48.5)$, respectively; the improvements from baseline were statistically significant $(p<0.001)$. Both PCS and MCS mean $(95 \% \mathrm{Cl})$ scores at 12 months were lower than 50 , i.e., the US population norm. 
Table 4

Differences in SF-36 mean scores (mixed effect models)

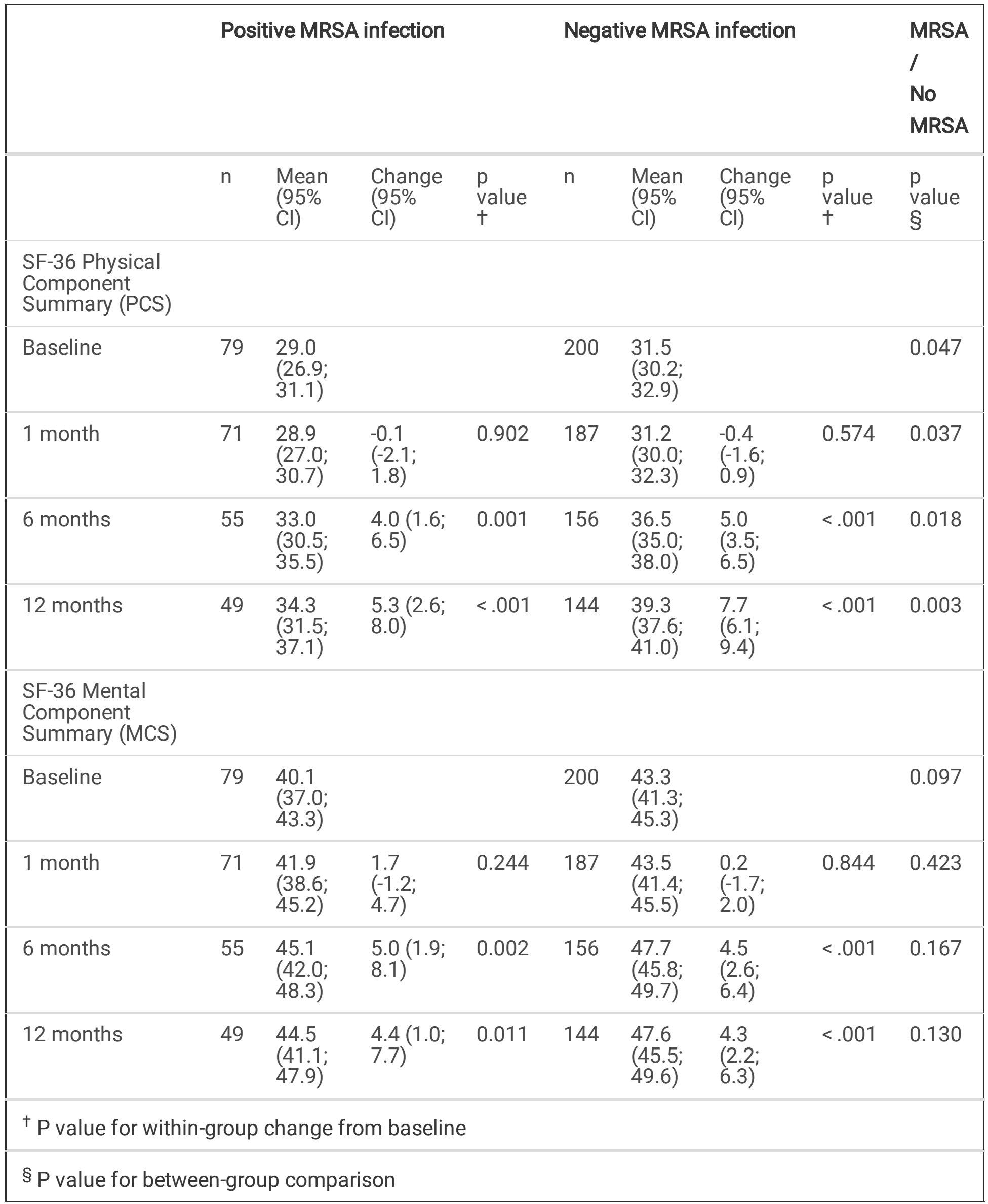


Statistically significant improvements were similarly observed in PMS scores at 6 and 12 months.

Analyses performed on the data from the "per protocol population" produced results with no qualitative differences from those performed on the data from the "full analysis population" (data not shown).

Table 5 summarizes the results of Katz ADL scores from baseline through the course of follow-up. Table 6 summarizes the changes in Katz ADL scores between FU visits and baseline using data from patients with scores available both at baseline and at the relevant follow-up. Similar to the results from SF-36 PCS and PMS, the mean (SD) score at 1 month [4.4 (2.0)] decreased slightly from the baseline [4.7 (1.9)], and as in the case of SF-36 PCS scores, the decrease was not statistically significant $(p=0.070)$ (Table 6). At 6 and 12 months (full analysis population) the mean (SD) scores rose from 4.6 (1.9) at baseline to 5.3 (1.5) and 5.5 (1.2), respectively ( $p<0.001$ in both cases). At the individual patient level, approximately half of the patients maintained their independence level at each FU; some became more independent at 6 and 12 months ( $n=76,38.4 \%$ and $n=71,39.4 \%$, respectively) whereas a few worsened and became more dependent $(n=20,10.1 \%$ at 6 months and $n=15,8.3 \%$ at 12 months) compared to baseline (Table 5).

Table 5

Local laboratory measurement over follow-up

\begin{tabular}{|c|c|c|c|}
\hline \multicolumn{4}{|c|}{ Visit } \\
\hline Variable & $\begin{array}{l}\text { Baseline } \\
N=292\end{array}$ & $\begin{array}{l}6 \text { months } \\
\mathrm{N}=216\end{array}$ & $\begin{array}{l}12 \text { months } \\
\mathrm{N}=196\end{array}$ \\
\hline \multicolumn{4}{|c|}{$\mathrm{HbA} 1 \mathrm{c}[\mathrm{mmol} / \mathrm{mol}]$} \\
\hline $\mathrm{n}$ & 59 & 39 & 39 \\
\hline Mean (sd) & $42.4(13.2)$ & $38.2(10.1)$ & $36.3(12.2)$ \\
\hline \multicolumn{4}{|c|}{ C-reactive protein $[\mathrm{mg} / \mathrm{L}]$} \\
\hline $\mathrm{n}$ & 254 & 114 & 101 \\
\hline Mean (sd) & $76.3(91.6)$ & $13.3(24.9)$ & $7.7(18.9)$ \\
\hline \multicolumn{4}{|c|}{ White blood cell (WBC) count $[1000 / \mu \mathrm{l}]$} \\
\hline $\mathrm{n}$ & 282 & 110 & 100 \\
\hline Mean (sd) & $9.2(3.7)$ & $7.5(6.0)$ & $7.0(2.2)$ \\
\hline \multicolumn{4}{|c|}{ Erythrocyte sedimentation rate $[\mathrm{mm} / \mathrm{hr}]$} \\
\hline $\mathrm{n}$ & 126 & 50 & 47 \\
\hline Mean (sd) & $53.5(36.3)$ & $17.9(20.8)$ & $20.6(18.9)$ \\
\hline
\end{tabular}


Table 6

Change in Katz ADL sum scores

\begin{tabular}{|c|c|c|c|c|}
\hline Variable & Baseline & 1 month & Change from baseline & $P$ value \\
\hline KATZ ADL sum score & & & & $0.070^{\dagger}$ \\
\hline$n$ & 250 & 250 & 250 & \\
\hline Mean (sd) & $4.7(1.9)$ & $4.4(2.0)$ & $-0.2(2.0)$ & \\
\hline Median (Q1; Q3) & $6.0(4.0 ; 6.0)$ & $5.0(3.0 ; 6.0)$ & $0.0(-1.0 ; 0.0)$ & \\
\hline \multirow[t]{2}{*}{ Min; Max } & $0.0 ; 6.0$ & $0.0 ; 6.0$ & $-6.0 ; 6.0$ & \\
\hline & Baseline & 6 months & Change from baseline & $P$ value \\
\hline KATZ ADL sum score & & & & $<.001^{\dagger}$ \\
\hline$n$ & 198 & 198 & 198 & \\
\hline Mean (sd) & $4.6(1.9)$ & $5.3(1.5)$ & $0.7(2.1)$ & \\
\hline Median (Q1; Q3) & $6.0(3.0 ; 6.0)$ & $6.0(5.0 ; 6.0)$ & $0.0(0.0 ; 2.0)$ & \\
\hline \multirow[t]{2}{*}{ Min; Max } & $0.0 ; 6.0$ & $0.0 ; 6.0$ & $-6.0 ; 6.0$ & \\
\hline & Baseline & 12 months & Change from baseline & $P$ value \\
\hline KATZ ADL sum score & & & & $<.001^{\dagger}$ \\
\hline$n$ & 180 & 180 & 180 & \\
\hline Mean (sd) & $4.6(1.8)$ & $5.5(1.2)$ & $0.9(1.9)$ & \\
\hline Median (Q1; Q3) & $6.0(3.0 ; 6.0)$ & $6.0(6.0 ; 6.0)$ & $0.0(0.0 ; 2.0)$ & \\
\hline Min; Max & $0.0 ; 6.0$ & $0.0 ; 6.0$ & $-6.0 ; 6.0$ & \\
\hline \multicolumn{5}{|c|}{$\begin{array}{l}\text { Only data from patients with scores available both at baseline and at the relevant follow-up were used } \\
\text { for analysis. }\end{array}$} \\
\hline \multicolumn{5}{|c|}{ Min: minimum; max: maximum } \\
\hline
\end{tabular}

According to the assessment of physicians at individual sites, the cure rate at 1, 6, and 12 months was $4.5 \%$ (12/265), 36.8\% (78/212), and 62.1\% (118/190), respectively. Complete case analyses showed similar results.

In-hospital complications and re-hospitalization: 
Forty-one patients experienced in-hospital complications that led to prolonged hospitalization or readmission; ten patients died of such in-hospital complications. The risk (\% [95\% Cl]) of in-hospital complication was $14.1 \%(10.3 ; 18.7)$ based on the number of the full analysis population and $18.9 \%$ $(13.9 ; 24.7)$ based on the sensitivity analysis (i.e., analysis including only patients who either completed the 1-year FU or who experienced at least one in-hospital complication).

Not counting the hospitalization at baseline, patients were reported to be re-hospitalized due to infection at a median $(\mathrm{Q} 1 ; \mathrm{Q} 3)$ of $1.0(0.0 ; 1.0)$ time during the study period and received surgical treatments at a median (Q1; Q3) of $1.0(0.0 ; 3.0)$ time. The overall risk (\% $[95 \% \mathrm{Cl}])$ of patients being re-hospitalized during the study period was $53.8 \%(47.9 ; 59.6)$. Sensitivity analysis of patients who had completed the 1 -year FU and/or with a record of re-hospitalization showed a slightly higher re-hospitalization risk of $63.4 \%$ (57.1; 69.4).

\section{Discussion}

The AO Trauma CPP Bone Infection Registry offers insight into the epidemiology and outcomes of S. aureus infections involving long bones and joints. A few key aspects are addressed below.

The study showed that nearly $60 \%$ of the patients had been treated for the same infection within the three years before they were enrolled in the current study. These patients had received a median number of two prior treatments. At least one patient had received as many as 20 prior orthopedic treatments, demonstrating the chronic nature of $\mathrm{S}$. aureus long-bone infection. This clinical finding is consistent with the recent discoveries on the unique pathogenic mechanisms of $S$. aureus in orthopedic infections. These include: 1) biofilm formation on the implant (15) and necrotic bone $(16,17), 2)$ generation of staphylococcal abscess communities (SACs) in soft tissues and bone marrow (18-20), 3) intracellular infection (1), and 4) the ability to colonize the osteocyte-canalicular network of live cortical bone $(21,22)$.

Second, less than two thirds of the patients were judged to be "cured" 12 months after treatment. This underlines the previously mentioned chronic nature of these long-bone infections. Although the current cure rate was low in comparison to what has been reported historically (i.e., $80-100 \%$ for both FRIs and prosthetic joint infections) $(5,23)$, a true comparison is not possible because there is no objective definition of "cure". Caution also should be taken while interpreting the current cure rate because of the heterogeneity of the patient population in terms of the infection stage at the start of the study.

Third, although patients' mental and physical state in general improved at the end of the study period based on the SF-36, PMS, and Katz ADL scores, the health state of the patients was still worse than the average of the normal US population as measured by the SF-36 scores. This underscores the serious effect $\mathrm{S}$. aureus bone infection can exert on patients' quality of life.

Limitations 
The current study has several limitations. 1) Since it was decided to accept patients previously diagnosed with long-bone infection, the baseline status of the patient population was heterogeneous with regard to the chronicity and progression of the infection. Although we have presented the outcome of the patients after the current treatments, the readers are advised to interpret the timing of the outcomes with caution, keeping in mind that the starting population was heterogeneous. 2) Although the current study aimed to capture a global picture of long-bone infections, the current patient population was unevenly distributed among the geographical locations. Some regions were underrepresented (e.g., South America, Middle East and Southeast Asia) or not represented at all (e.g., Africa and Australia). Due to the high incidence and widespread nature of antimicrobial resistant infections, bone and joint infections are a major healthcare burden in LMIC (low- and middle-income countries) (24), therefore, the underrepresentation of LMIC is particularly noticeable. 3) For the sake of having a patient population with some degree of homogeneity, the current study focused on mono and polymicrobial S. aureus infections. Although S. aureus is the most common causative pathogen, approximately $70 \%$ of the bone and joint infections are associated with other species $(3,25-27)$, and therefore not represented in the AO Trauma CPP Bone Infection Registry. 4) Although the current study showed that more than half of the patients $(n=151$, $53.2 \%$ ) received a multistage procedure, which is in agreement with the literature value (5), this number should be taken with caution because the reporting was not consistent among the investigational sites. For example, some sites reported a multistage surgery as one surgery, while others may have reported the baseline surgery of a multistage surgery as the first surgery and all subsequent stages as additional surgeries. 5) The AO Trauma CPP Bone Infection Registry suffered from a high dropout rate (8). Nevertheless, per protocol analyses and sensitivity analyses produced qualitatively similar results. Additionally, in our analyses using the full analysis population, we presume that the high dropout rate did not affect the interpretation of the data.

\section{Conclusions}

The AO Trauma CPP Bone Infection Registry demonstrated a highest proportion of MRSA vs. MSSA long bone and joint infection in North America, followed by Asia and then Central Europe. Of this population, nearly $60 \%$ of the patients had been previously treated for reasons related to the current infection. One year after the treatment, less than two thirds of the patients were reported to be clinically cured, and both the mental and health status of the patients were, on average, worse than the general US population. The AO Trauma CPP Bone Infection Registry is an annotated biospecimen repository that can be utilized to elucidate relationships between patient demographics, comorbidities, treatment modality, patent-specific host immunity to the causal pathogen(s), and outcomes, in prospective studies.

\section{List Of Abbreviations}

AEs adverse events

FRI Fracture-related infection 
FU Follow-up

Katz ADL Katz Index of Independence in Activities of Daily Living

LMIC Low- and middle-income countries

MCS Mental component summary scores

MRSA Methicillin resistant S. aureus

MSSA Methicillin sensitive S. aureus

PCS Physical component summary scores

PMS Parker Mobility Score

SD Standard deviation

SF-36 Short Form-36

\section{Declarations}

\section{Ethical approval and consent to participate}

All procedures performed in studies involving human participants were in accordance to the ISO 9001 guidelines and the 1964 Helsinki Declaration, including its later amendments or comparable ethical standards. The study was registered at ClinicalTrials.gov and approved by the Virginia Commonwealth University Institutional Review Board (Approval \#HM20006017) and at each site's local ethics committee.

Written informed consent was obtained from all individual participants included in the study.

Availability of data and materials

The datasets used and/or analyzed during the current study are available from the corresponding author on reasonable request.

Consent for publication:

Not Applicable

$\underline{\text { Competing interests }}$

SLK: Research support from AO Trauma, DePuy Synthes, NIH (P50 AR072000), PCORI and Journal Editor Sage Publications 
EMS: Research support from AO Trauma, NIH (P50 AR072000), and Journal Editor (Arthritis Research \& Therapy, Journal of Orthopaedic Research).

MM: Research support from AO Trauma,

WJM: received research support from AO Trauma, is consultant for Depuy Synthes and member of the speakers bureau of Zimmer Biomet.

MB: Affiliation and Disclosure:

Franchise Medical Director, Preclinical Clinical Medical Trauma CMF Biomaterials

Depuy Synthes

FL: Research support from AO Trauma, Journal Deputy Editor Sage Publication

KS, XZ, CE, MM, JS, MS, MN, JB, DS, KY, BQ, YL: none reported

Authors' contributions

SLK: design and oversight of the study, drafting and review of manuscript.

EMS: design the study, drafting and review of manuscript.

MM, Principal investigator at study site. Writing of the manuscript.

WJM, MB, FL, DS, JS, MS, RB, VA, KY, JB, MN, KS, XZ, BQ, YL: Principal investigator at study site. Review/ corrections of the manuscript.

\section{Acknowledgements}

The authors thank the team at AO Clinical Investigation and Documentation for conducting the study and providing scientific, statistical, and writing support.

\section{Funding}

This study was funded by the AO Foundation via the AO Trauma Clinical Priority Program on "Bone Infection".

\section{References}

1. Masters EA, Trombetta RP, de Mesy Bentley KL, Boyce BF, Gill AL, Gill SR, et al. Evolving concepts in bone infection: redefining "biofilm", "acute vs. chronic osteomyelitis", "the immune proteome" and "local antibiotic therapy". Bone Res. 2019;7:20. 
2. Saeed K, McLaren AC, Schwarz EM, Antoci V, Arnold WV, Chen AF, et al. 2018 international consensus meeting on musculoskeletal infection: Summary from the biofilm workgroup and consensus on biofilm related musculoskeletal infections. J Orthop Res. 2019;37(5):1007-17.

3. Metsemakers WJ, Kuehl R, Moriarty TF, Richards RG, Verhofstad MHJ, Borens O, et al. Infection after fracture fixation: Current surgical and microbiological concepts. Injury. 2018;49(3):511-22.

4. Zimmerli W, Trampuz A, Ochsner PE. Prosthetic-joint infections. The New England journal of medicine. 2004;351(16):1645-54.

5. Bezstarosti H, Van Lieshout EMM, Voskamp LW, Kortram K, Obremskey W, McNally MA, et al. Insights into treatment and outcome of fracture-related infection: a systematic literature review. Archives of orthopaedic and trauma surgery. 2019;139(1):61-72.

6. Parvizi J, Gehrke T, Mont MA, Callaghan JJ. Introduction: Proceedings of International Consensus on Orthopedic Infections. J Arthroplasty. 2018.

7. Schwarz EM, Parvizi J, Gehrke T, Aiyer A, Battenberg A, Brown SA, et al. 2018 International Consensus Meeting on Musculoskeletal Infection: Research Priorities from the General Assembly Questions. J Orthop Res. 2019;37(5):997-1006.

8. Kates SL, Hurni S, Chen MS. Development and challenges in setting up an international bone infection registry. Arch Orthop Trauma Surg. 2019.

9. Quan H, Li B, Couris CM, Fushimi K, Graham P, Hider P, et al. Updating and validating the Charlson comorbidity index and score for risk adjustment in hospital discharge abstracts using data from 6 countries. AmJ Epidemiol. 2011;173(6):676-82.

10. Ware JE, Jr. SF-36 health survey update. Spine. 2000;25(24):3130-9.

11. Ware JE, Jr, Kosinski M, Dewey JE. How to Score - Version 2 of the SF-36 Health Survey ( Standard \& Acute Forms ). 3rd ed. Lincoln, Rhode Island 02865: QualityMetric, Incorporated; 2001 5/17/2001.

12. Parker MJ, Palmer CR. A new mobility score for predicting mortality after hip fracture. J Bone Joint Surg Br. 1993;75(5):797-8.

13. KATZ S. Assessing self-maintenance: activities of daily living, mobility, and instrumental activities of daily living. J AmGeriatrSoc. 1983;31(12):721-7.

14. KATZ S, Downs TD, Cash HR, Grotz RC. Progress in development of the index of ADL. Gerontologist. $1970 ; 10(1): 20-30$.

15. Nishitani K, Sutipornpalangkul W, de Mesy Bentley KL, Varrone JJ, Bello-Irizarry SN, Ito H, et al. Quantifying the natural history of biofilm formation in vivo during the establishment of chronic implant-associated Staphylococcus aureus osteomyelitis in mice to identify critical pathogen and host factors. J Orthop Res. 2015;33(9):1311-9.

16. Lew DP, Waldvogel FA. Osteomyelitis. Lancet. 2004;364(9431):369-79.

17. Birt MC, Anderson DW, Bruce Toby E, Wang J. Osteomyelitis: Recent advances in pathophysiology and therapeutic strategies. Journal of orthopaedics. 2017;14(1):45-52. 
18. Cheng AG, Kim HK, Burts ML, Krausz T, Schneewind O, Missiakas DM. Genetic requirements for Staphylococcus aureus abscess formation and persistence in host tissues. FASEB J. 2009;23(10):3393-404.

19. Varrone JJ, de Mesy Bentley KL, Bello-Irizarry SN, Nishitani K, Mack S, Hunter JG, et al. Passive immunization with anti-glucosaminidase monoclonal antibodies protects mice from implantassociated osteomyelitis by mediating opsonophagocytosis of Staphylococcus aureus megaclusters. J Orthop Res. 2014;32(10):1389-96.

20. Yokogawa N, Ishikawa M, Nishitani K, Beck CA, Tsuchiya H, Mesfin A, et al. Immunotherapy synergizes with debridement and antibiotic therapy in a murine 1-stage exchange model of MRSA implant-associated osteomyelitis. J Orthop Res. 2018;36(6):1590-8.

21. de Mesy Bentley KL, MacDonald A, Schwarz EM, Oh I. Chronic Osteomyelitis with Staphylococcus aureus Deformation in Submicron Canaliculi of Osteocytes: A Case Report. JBJS Case Connect. 2018;8(1):e8.

22. de Mesy Bentley KL, Trombetta R, Nishitani K, Bello-Irizarry SN, Ninomiya M, Zhang L, et al. Evidence of Staphylococcus Aureus Deformation, Proliferation, and Migration in Canaliculi of Live Cortical Bone in Murine Models of Osteomyelitis. J Bone Miner Res. 2017;32(5):985-90.

23. Tande AJ, Patel R. Prosthetic joint infection. Clinical microbiology reviews. 2014;27(2):302-45.

24. Geurts J, Hohnen A, Vranken T, Moh P. Treatment strategies for chronic osteomyelitis in low- and middle-income countries: systematic review. Tropical medicine \& international health : TM \& IH. 2017;22(9):1054-62.

25. Calhoun JH, Manring MM, Shirtliff M. Osteomyelitis of the long bones. Seminars in plastic surgery. 2009;23(2):59-72.

26. Murillo O, Grau I, Lora-Tamayo J, Gomez-Junyent J, Ribera A, Tubau F, et al. The changing epidemiology of bacteraemic osteoarticular infections in the early 21 st century. Clinical microbiology and infection : the official publication of the European Society of Clinical Microbiology and Infectious Diseases. 2015;21(3):254.e1-8.

27. Kuehl R, Tschudin-Sutter S, Morgenstern M, Dangel M, Egli A, Nowakowski A, et al. Time-dependent differences in management and microbiology of orthopaedic internal fixation-associated infections: an observational prospective study with 229 patients. Clinical microbiology and infection : the official publication of the European Society of Clinical Microbiology and Infectious Diseases. 2019;25(1):76-81.

\section{Figures}




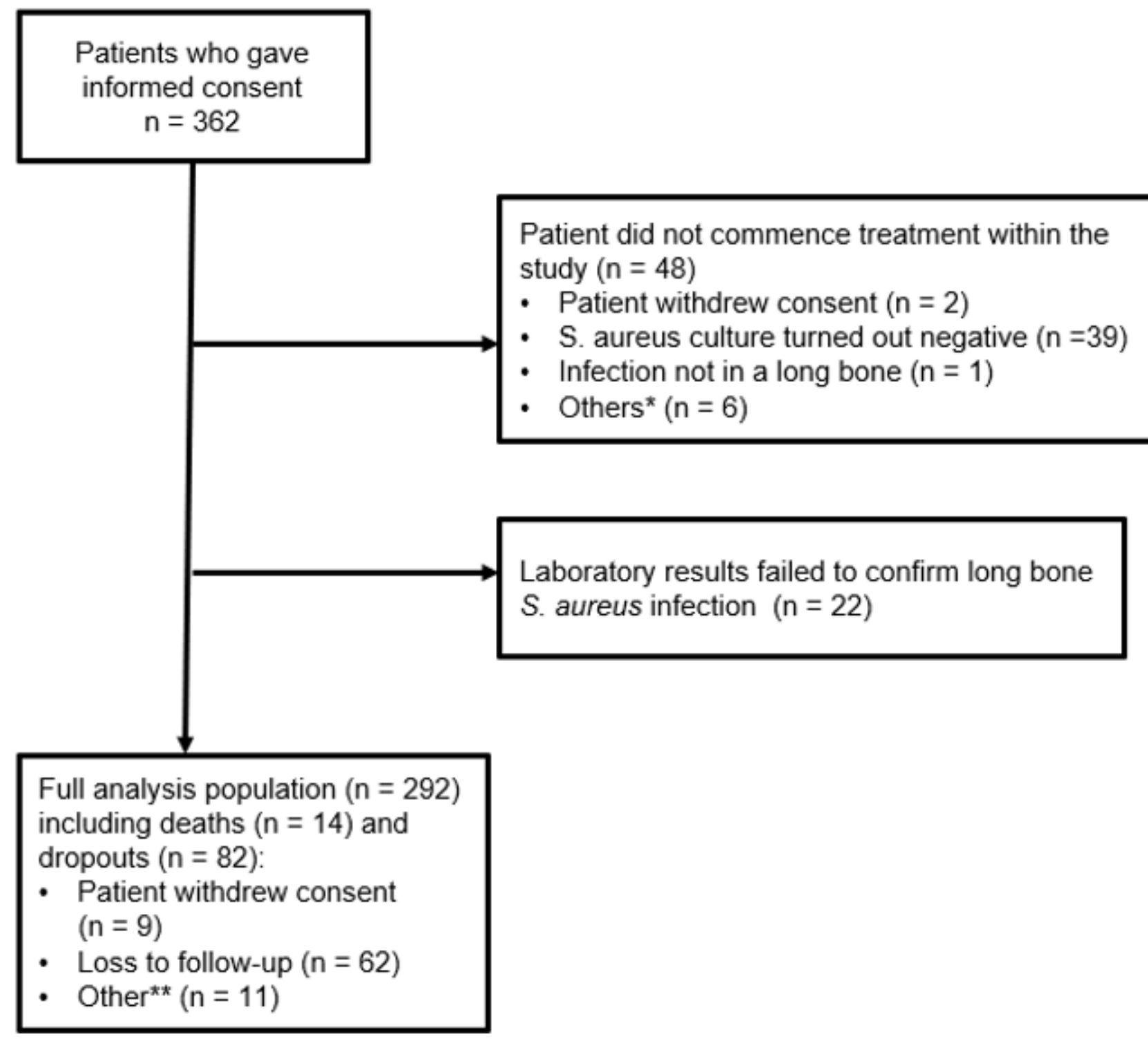

* Reasons include: infection did not involve a long bone, culture negative for $\mathrm{S}$. aureus infection, and patient moved to a different hospital

** Reasons include: patients did not plan on coming back for follow-ups, patient withdrawal, insurance coverage issue, and unknown exclusion

Figure 1

Patient recruitment diagram 